\title{
A EXPANSÃo DA LÍNGUA ITALIANA NA PENÍNSULA E A SALA DE AULA DE ITALIANO COMO LINGUA ESTRANGEIRA*
}

\author{
Ana Maria Chiarini ${ }^{* *}$
}

\begin{abstract}
Resumo: Este trabalho se propõe a oferecer um panorama do processo de italianização lingüística da península italiana, acentuando a riqueza e a complexidade da situação dele resultante. Partindo da premissa de que a sala de aula de italiano como LE não está, nem deve estar, imune à dinâmica da lingua no cenário onde é falada, o objetivo deste texto é sensibilizar o profissional do ensino ou o aprendiz para tal dinâmica e evidenciar o fato de que apenas o conhecimento dessa realidade possibilitará a clareza para a definição de conteúdos lingüisticos e culturais das aulas e para um posicionamento mais crítico e seguro diante das incertezas e ambigüidades de um campo em saudável movimento.
\end{abstract}

Nós, professores de italiano como língua estrangeira, nos vemos, com freqüência, interpelados por questões de nossos estudantes ou por desafios colocados pelo material didático relativos à construção e à dinâmica da matériaprima importada na qual baseamos nosso trabalho: a língua italiana. Nos momentos em que essa língua - introduzida em nossa vida às custas de um alto investimento em horas de estudo e dedicação - assume a face hostil de produto estrangeiro, nada familiar, defrontamo-nos com o mal-estar

\footnotetext{
Recebido para publicação em setembro de 2005.

- Professora da Faculdade de Letras/UFMG.
} 
típico, inerente ao próprio ofício, de todo professor de LE: a condição de dependência em relação a um contexto do qual não participamos nem direta nem indiretamente, tendo, no entanto, que nos pautar, na definição do conteúdo de nossas aulas, pela dinâmica da língua acionada por seus falantes. No caso específico da língua italiana, em que tal dinâmica vem serido fortemente acelerada nas últimas décadas, como mostrarei a seguir, esse mal-estar pode vir a ser acentuado, causando um sentimento de incerteza e insegurança no profissional do ensino.

O presente trabalho parte da premissa de que as salas de aula de italiano como LE não são - e não devern ser imunes aos movimentos do rico e variado espaço lingüístico italiano. Propõe-se a oferecer um panorama do processo de italianização lingüística da península, enfatizando os desafios introduzidos no âmbito da prática didática e a necessidade de enfrentar esses desafios a partir do desenvolvimento de uma competência sociolingüística e de um conhecimento mais aprofundado da história da língua.

\section{A expansão da língua italiana e o alargamento do repertório dos falantes na península}

Até a metade do século $X X$, o italiano era aprendido, pela grande maioria da população da península, como uma segunda língua. Seu uso restringia-se à escrita e a contextos específicos e limitados: aqueles que, pela formalidade e oficialidade, assemelhavam-se ao domínio da palavra impressa. O italiano falado constituía-se numa entidade quase virtual e a dimensão da oralidade era aquela em que os vários dialetos assumiam uma posição privilegiada.

Convém explicitar, desde já, a diferença básica entre dialeto e língua. Segundo DARDANO (1991) - resumindo 
em poucas palavras uma história de vários séculos - com o fim da unidade política do mundo romano, o latim vulgar se fragmentou numa multiplicidade de dialetos e, sucessivamente, alguns deles se impuseram sobre outros, transformando-se em verdadeiros símbolos de comunidades nacionais, ou seja, línguas nacionais. É famosa a afirmação provocativa que defende que uma língua nada mais é do que um dialeto dotado de um exército e de uma marinha. ${ }^{1}$

No caso do italiano, apesar de presente desde a época de Dante, a chamada Questão da Língua, isto é, a discussão em torno de qual seria a verdadeira língua italiana, acirrouse durante o Renascimento com uma disputa entre vários intelectuais de renome. Do debate, saiu vencedora a proposta de Pietro Bembo, veneziano, mas defensor da língua literária florentina. Para o sucesso dessa proposta, alguns elementos foram fundamentais, como a influência da Igreja, que, desde o início do século $X V$, adotara o toscano-florentino como segunda língua, o apoio de Aldo Manuzio, grande editor, também veneziano, que colaborou para tornar cada vez mais acessíveis os livros em língua florentina e o fato de ser esta a única proposta de caráter normativo e passível de ser seguida a partir dos modelos privilegiados, ou seja, Petrarca, na poesia, e Boccaccio, na prosa.

Ressalte-se, portanto, que esse toscano-florentinoitaliano já nasceu como língua de cultura, tendo como modelo obras escritas dois séculos antes de sua legitimação por Bembo. Foi aprendido por uma elite, pouco significativa em termos numéricos, mas bastante respeitável no que se refere ao poder e prestígio social, enquanto as necessidades expressivas da maioria dos habitantes da península continuavam a ser satisfeitas pelos dialetos.

SANTIPOLO (2002) atribui sua autoria a Max Weinreich, enquanto STEINBERG (1997) a atribui a Gianrenzo Clivio. 
Uma outra etapa importante da Questão da Língua apresentou-se, em meados do século XIX, quando Alessandro Manzoni, milanês, se propôs a realizar uma longa pesquisa sobre a língua falada em Florença, tentando dar mais vigor e atualidade àquela proposta em 1525, em Prose della Volgar Lingua, de Bembo. O resultado do trabalho foi exposto na edição de 1840 de seu romance I Promessi Sposi, considerado o modelo renovado de língua literária e, conseqüentemente, de língua nacional. No entanto, o empenho de Manzoni e as preocupações do novo governo unificado não foram suficientes para consolidar o italiano como língua de comunicação antes do século XX.

Tullio De Mauro, em Storia Linguistica dell'Italia Unita, de 1963, aponta uma série de fatores, aceita por estudiosos em geral, como responsável pela difusão do italiano entre falantes de dialetos diversos, num movimento lento e paulatino:

- a industrialização e a urbanização (movimentando massas de trabalhadores de muitos pontos do país para as regiões industrializadas),

- o serviço militar obrigatório (que, na Itália, é cumprido em cidades distantes da própria residência),

- a burocracia (com sua proposta de língua neutra e impessoal),

- a I Guerra Mundial (que concentrou grande número de soldados nas zonas de conflito),

- a crescente escolarização (bastante criticada, no entanto, pelo papel relativamente tímido desempenhado em face dos outros fatores),

- a imprensa escrita, limitada aos alfabetizados, e, em especial, o rádio, o cinema e a televisão.

Hoje, ao longo desse processo acionado por várias frentes, pode-se afirmar que a população vem se apropriando 
da língua de Dante, Petrarca e Boccaccio, adaptando-a e recriando-a, segundo suas necessidades. Enfim, em especial durante o século $X X \mathrm{e}, \mathrm{com}$ mais visibilidade, a partir dos anos 50 , o italiano foi adotado, manuseado e enxertado por falantes das vinte regiões. Com sotaque, sintaxe e léxico particulares, imprimiu-se um ritmo inédito à mudança lingüística. Pelo que indica a bibliografia da área, a espantosa estabilidade da língua, em confronto com as outras línguas européias, dada sua forte tradição escrita, foi, assim, finalmente rompida.

Aqui é importante enfatizar que a mudança em curso no italiano reveste-se de uma aura particular. Nesse sentido, não pode ser analisada da mesma forma que o movimento do português ou inglês, mas como uma novidade, uma aceleração ímpar devido à história que a precede. Com essa afirmação parecem concordar muitos estudiosos de renome. Segundo BERRUTO (1987:55), por exemplo:

"[...] é certo que parece estar acontecendo na Itália, ao longo de algumas décadas, aquilo que em outros países europeus aconteceu ao longo de alguns séculos. O processo acelerado de difusão e expansão da língua nacional levou de uma situação de monolingüismo dialetal difuso, com uma certa proporção de bilingüismo (italiano-dialeto), a um bilingüismo difuso, com uma boa proporção de monolíngües italianos." ${ }^{2}$

2 "[...] è certo che sembra stia succedendo in Italia nel giro di alcuni decenni ciò che in altri paesi europei era avvenuto lungo qualche secolo, col processo accelerato di diffusione ed espansione della lingua nazionale che ha fatto passare da una situazione di diffuso monolinguismo dialettale con una certa proporzione di bilingui (italiano-dialetto) a un diffuso bilinguismo, con una buona proporzione di monolingui italiani." (A tradução dessa citação e de todas as outras deste texto são minhas) 
Em relação ao uso da língua nacional na atualidade, podese afirmar que é cada vez mais extenso. Às custas de um uso mais restrito do dialeto, tanto em casa quanto em outros ambientes, na maioria das regiões, os jovens e as crianças são aqueles que contribuem em especial para sua generalização. É interessante pensar, como ressalta LORENZETTI (2002:19) que, nos anos 50, "inicia em muitas famílias italianas uma verdadeira revolução lingüística, que consistia em falar uma língua (o dialeto) entre os cônjuges e com os velhos, e uma outra língua (o italiano) com os filhos ${ }^{\prime \prime}$. Pesquisas realizadas pela agência DOXA, de abrangência nacional, documentam as mudanças aceleradas nesse plano: segundo os dados de 1982, um quinto dos falantes eram dialetófonos, enquanto os dados de 1991 indicam que cerca de $80 \%$ da população eram capazes de usar o italiano e que apenas $12 \%$ ou $14 \%$ faziam uso exclusivo dos dialetos (COVERI, BENUCCI \& DIADORI, 1998:232). De acordo com outro estudo da DOXA, no ano de $1995,44,4 \%$ usavam apenas o italiano, $48,7 \%$ usavam tanto o dialeto quanto o italiano e $6,9 \%$ usavam apenas o dialeto (DE MAURO \& VEDOVELLI, 1999:148 apud SANTIPOLO, 2002:30).

É óbvio que o alargamento do repertório dos falantes em geral, com todas as suas implicações, passou a preocupar os teóricos, pouco habituados à tal dinâmica, rara na história da língua. Assim, diversos estudos começaram a ser produzidos com o intuito de contemplar as mudanças em ato: nos anos 70, tiveram início as pesquisas sobre a língua oral e, na década de 80 , aquelas sobre variação lingüística.

"Porém, nesse cenário, cabe destacar que até a percepção de tais mudanças atravessam a

3 "inizia in molte famiglie italiane una vera e propria rivoluzione linguistica, consistente nel parlare in una lingua (il dialetto) tra coniugi e con gli anziani, in un'altra lingua (l'italiano) con i figli." 
esfera do político. As avaliações a respeito dos movimentos da língua - algumas vezes, considerados reais mudanças, outras vezes, apenas traços acentuados da tradição, emersos ao longo dos anos - também dependem de uma avaliação política da questão. Ao que parece, os dados das pesquisas não são suficientes para garantir uma visão unânime ou harmônica dos teóricos, pois as bases da interpretação divergem. Cito dois debates para ilustrar tais discordâncias."

SABATINI (1985) escreve um artigo importante sobre um personagem que entra em cena com a expansão da italofonia na península: o italiano de uso médio. Para o lingüista, essa variante, que tem como ponto de partida a língua oral, contrapõe-se à língua standard oficial, modelo ideal ligado à tradição literária. Sabatini, nesse trabalho, reconhece 35 traços característicos da nova variante, tanto fonológicos quanto morfossintáticoselexicais,nosquaisSERIANNI(1986)concentra sua crítica para fazer uma defesa da norma. Em "Il problema della norma linguistica dell'italiano", de 1986, SERIANNI vê a consolidação da dinâmica da língua, ao longo dos anos, numa variante lingüística unitária, sem marcas regionais: um italiano sem adjetivos. Portanto, se Sabatini aponta a novidade do avanço da língua oral, SERIANNI evidencia a sobrevivência da língua escrita. Se o primeiro apresenta traços da oralidade, que colaboram para o deslocamento do eixo normativo da língua, o segundo elege a língua burocrática como salvaguarda da língua escrita e, analisando textos de fotonovelas, romances populares e revistas em quadrinhos, demonstra a persistência da norma tradicional em contraposição aos traços apontados pelo colega. 
CASTELLANI (1991), por sua vez, escreve o artigo "Italiano dell'uso medio o italiano senz'aggettivi?" ("Italiano de uso médio ou italiano sem adjetivos?"). Tendo como parâmetro a língua florentina e como interlocutor o mesmo SABATINI (1985), reconhece na tradição os traços característicos do italiano falado por um estrato médio da população, subestimando a novidade do fenômeno. O próprio título de Castellani, encontrado também no corpo do texto de SERIANNI (1986), é uma resposta aos estudos que, ainda hoje, são referências essenciais por tentarem dar conta das transformações, focalizando aspectos e adjetivando os novos perfis da língua: italiano popular unitário (DE MAURO, 1970), italiano popular (CORTELAZZO, 1972), italiano tendencial (MIONI, 1983), italiano de uso médio (SABATINI, 1985), italiano neo-standard (BERRUTO, 1987).

“É interessante observar que SABATINI (1985), na verdade, não nega a historicidade desses traços lingüísticos, mas reivindica novidade para o fato de que tais traços, assumidos na língua falada nacionalmente, estejam movimentando a língua literária, tida como modelo, e alterando a norma."

As apreciações quanto a essa língua em construção, considerado o processo aqui exposto, também estão distantes de umacordo. Abandonando um pouco ocampo da Lingüística, em 1964, uma figura marcante na vida intelectual italiana, Pier Paolo PASOLINI (1986), já tecia comentários críticos, no artigo intitulado "Novas questões lingüísticas". Se, por um lado, há um tom catastrófico, quase apocalíptico, por parte do autor, há, por outro, uma profunda percepção de algumas tendências dessas transformações na língua. PASOLINI refere-se a uma 
revolução (em contraposição à evolução das línguas inglesa e francesa), à formalização das línguas setoriais, em curso naqueles anos, e à mudança do modelo lingüístico do centro da península (Toscana) para o norte industrial. Centra sua atenção no avanço da tecnologia, sem dúvida, o eixo contra o qual investe todo seu poder crítico, e denuncia a prevalência da finalidade comunicativa sobre a finalidade expressiva nesse contexto.

No mesmo artigo, faz uma análise do italiano de alguns dos escritores mais famosos do período, bastante ilustrativa das dificuldades expressivas de quem partia da realidade lingüística do país para produzir ficção. Segundo PASOLINI, Carlo Cassola e Giorgio Bassani, por exemplo, são nostálgicos, que "mesclam ao estilo sublimis (sic) [...] uma língua falada como língua paterna, de pais naturalmente burgueses" (1986:20), a língua de Alberto Moravia "é uma simulação do italiano médio" (1986:21), Elsa Morante "finge que o italiano existe, e que é a língua que o espírito lhe propõe neste mundo para se exprimir" (1986:21), enquanto Carlo Emilio Gadda, em relação ao italiano, "como todo escritor de valor julga-o absolutamente infreqüentável" (1986:22).

Em 1965, o autor continua o ataque à nova hegemonia tecnológica. Aludindo ao hábito introduzido no período de se responder "exato" a uma pergunta, ao invés de um simples "sim", profetiza que "[p]aradoxalmente, é concebível a hipótese que aos poucos exato substitua sim. E que portanto a Itália aos poucos se torne o Bel Pese onde soa o exato" (PASOLINI, 1986:82).

Retornando ao âmbito mais estritamente lingüístico do debate, a partir de uma perspectiva teórica diferente e com um objetivo crítico muito distante daquele de Pasolini, CASTELLANI POLLIDORI (1994) cita a banalização, a simplificação e o empobrecimento da língua. Para a lingüista, 
devido ao aumento do número de falantes, estaria em curso a constituição de uma espécie de italiano básico, denominado "língua de plástico" (1994:10)4. A autora utiliza termos como "italiano de consumo" e "degradação" da língua, que se associam à "italianização de massa e ao avanço da oralidade pública" (1994:11)

SOBRERO (1994:42), obviamente respondendo à sua colega, numa defesa brilhante de uma língua viva, sustenta:

"O falado que vai se delineando, em definitivo, é estreitamente congruente com as mudanças da vida social, da história; è é um falado articuladíssimo, que explora a fundo as potencialidades produtivas da língua, não engessado pela adesão a um cânone de sabor literário, mas rico de recursos, com freqüência, simultaneamente disponíveis ao falante: do substrato dialetal à gíria, a essa ou aquela linguagem especial, do regionalismo à metáfora mais brilhante, do exagero à atenuação, à citação, do falado-falado ao falado-escrito, etc.

Não uma língua de plástico, portanto, mas uma língua plástica, isto é, uma língua que "tem consistência compacta, mas não rígida, que pode, assim, ser modelada e manter a nova forma assumida", como dita a definição de "plástico" no Nuovissimo Dardano. Eu

4 Aqui faço uso de um texto de 1994 de Ornella Castellani Pollidori, mas "La lingua di plastica" é o título de um artigo publicado em Studi Linguistici Italiani $16,1990$.

5 "lingua di plastica", "italiano di consumo", "degrado", "italianizzazione di massa e avanzata dell'oralità pubblica". 
diria uma língua-língua," finalmente: uma língua em pleno exercício de suas funções, depois de tantos séculos de stand-by. Ou melhor, de espera." ${ }^{\prime 6}$

Alarmismos à parte, parece unanimidade entre os estudiosos que a situação lingüística italiana hoje é marcada por uma grande diversidade e que o repertório dos italianos tornou-se mais complexo, com mais facetas empregadas e compreendidas por muitos. DE MAURO \& VEDOVELLI (1996), por exemplo, ressaltam as presenças simultâneas da língua nacional e dos dialetos: a língua nacional, não mais atrelada à língua literária - composta por variantes formais ou informais, escritas ou faladas -, e os dialetos, apresentandose como variantes locais ou mais ou menos italianizadas. É importante observar que, tentando fotografar tal diversidade, são inúmeros os estudos dedicados ao repertório lingüístico da península e às tendências apontados por $\mathrm{ele}^{7}$, bem como é significativa a grande preocupação dos estudiosos com a língua dos jovens, dos meios de comunicação em geral e dos chats e e-mails.

6 "Il parlato che si va profilando, in definitiva, è strettamente congruente con i mutamenti della vita sociale, della storia; ed è un parlato articolatissimo che sfrutta a fondo le potenzialità produttive della lingua, non ingessato nell'adesione a un canone di sapore letterario ma ricco di risorse spesso simultaneamente disponibili al parlante: dal sostrato dialettale al gergo, a questo o quel linguaggio speciale, dal regionalismo alla metafora scintillante, dall'esagerazione all'attenuazione, alla citazione, dal parlato-parlato al parlatoscritto ecc.

Non una lingua "di plastica" dunque, ma una lingua plastica, cioè una lingua che "ha consistenza compatta ma non rigida e può essere quindi modellata $e$ mantenere la nuova forma assunta" come suona la definizione di plastica nel Nuovissimo Dardano. Direi una lingua-lingua, finalmente: una lingua nel pieno esercizio delle sue funzioni dopo tanti secoli di stand-by. Anzi, di attesa."

7 É sintomático que L'Italiano Contemporaneo seja o título de duas obras recentes: uma de LORENZETTI (2002) e outra de D'ACHILLE (2003). 


\section{Entrando na sala de aula de italiano como Língua Estrangeira}

Neste ponto, cabe evidenciar o fato de que as salas de aula de italiano como LE não se encontram imunes à configuração do rico e variado espaço lingüístico italiano, produto de um percurso histórico peculiar. ${ }^{8}$ Em outras palavras, a apropriação da língua italiana por seus usuários, na Itália, pressiona o modelo de língua ensinado no Brasil e no mundo, estimulando alterações de ordem cultural, sintática, lexical e fonológica ou, pelo menos, colocando a questão: qual italiano ensinar? Isso posto, poderíamos afirmar que diversos traços constituintes do italiano contemporâneo e tendências apontadas por estudiosos configuram-se como desafios para os professores pela novidade de sua expansão ou da sistematicidade de seu uso em toda a península.

Muitas vezes, o profissional se vê obrigado a ensinar, com segurança e firmeza, o que não aprendeu nos livros didáticos de outras épocas (não tão passadas, é importante lembrar, dada a rapidez das mudanças já descritas) ou o que não viveu, devido aos vários quilômetros ou anos de distanciamento em relação à Itália. VEDOVELLI (1994) percebe as interferências no plano metodológico de uma realidade pontuada por diferenças regionais e locais que questionam a norma a ser proposta. Segundo o autor, num contexto de aquisição, ou de imersão no país da L2, as irregularidades são aceitas com maior facilidade, o que não acontece num contexto de instrução formal, onde o estudante tem uma expectativa mais voltada para um modelo regular de língua. Exemplos concretos podem aqui ser elencados para ilustrar algumas das

8 Nesse sentido, compartilho a posição de uma tradição de estudos da Lingüística Aplicada que defende uma estreita relação entre as salas de aula e os contextos que as circundam (BREEN, 1986; COLEMAN, 1996; HOLLIDAY, 1994). 
questões envolvendo essas inseguranças e irregularidades enfrentadas em nossa prática de sala de aula.

Logonos primeiros meses deaprendizagem, a pronúncia aberta ou fechada das vogais " $\mathrm{e}$ " $\mathrm{e}$ " $\mathrm{O}$ " apresenta-se como um ponto delicado: se, por um lado, a distinção entre os sons típica do modelo toscano atualmente não é mais observada, por outro lado, as realizações das variantes setentrionais são indubiamente aquelas de maior prestígio. A elisão dos artigos definidos " 10 " e "la" precedendo substantivos que iniciam em vogal também não se trata de questão simples. Ainda que seja obrigatória segundo a norma, a utilização de material autêntico como jornais, revistas e Internet coloca às claras o fato de que não é observada em muitos casos, apesar de nem sempre tal "desobediência" ser bem aceita?.

Em relação ao sistema verbal, pode-se afirmar que o italiano contemporâneo tem caminhado em direção a uma simplificação do italiano standard, constituindo, em princípio, uma vantagem para o contexto da sala de aula. Os tempos mais freqüentes são o presente do indicativo, o passato prossimo, o imperfeito do indicativo e o trapassato prossimo (LORENZETTI, 2002:75), o que deveria se refletir no material didático, inclusive no que diz respeito à ordem de introdução dessas estruturas. O futuro, por sua vez, vem sendo explicitamente subtituído pelo presente do indicativo acompanhado por advérbios de tempo que permitem a localização temporal (como em "ad aprile vado in Italia") e, hoje, é quase que reservado a previsões e dúvidas (como em "per il segno dello scorpione sarà finalmente una settimana positiva" ou "saranno le otto"). No entanto, a freqüente utilização em letras de canções populares, possivelmente pela facilidade das rimas, pode conduzir o

9 O motor Google apresentou, por exemplo, em novembro de 2005, 15.300 ocorrências de "la unica" para 1.880 .000 ocorrências de "l'unica" e apenas 15 ocorrências de "lo elefante" para 62.100 ocorrências de "l'elefante". 
estudante a conclusões equivocadas quanto à vitalidade desse tempo verbal. O modo subjuntivo, também perdendo terreno, mantém-se, entretanto, sinônimo de educação formal e conhecimento da língua e, talvez, possa funcionar como uma moeda de troca interessante a ser empregada na relação desigual com interlocutores nativos, contribuindo, ainda que com modéstia, para o empoderamento do aprendiz.

Quanto aos pronomes, uma dificuldade enfrentada desde sempre por falantes de português dedicados à aprendizagem do italiano, são considerados por muitos estudiosos como os maiores alvos de mudanças sensíveis na gramática da língua (LORENZETTI, 2002:78) e, sem dúvida, passam a exigir um cuidado maior em seu tratamento na sala de aula. O uso de "gli" como pronome indireto plural é o mais adequado à dimensão oral em toda a pensínsula hoje, mas "loro" ainda ocupa seu espaço em registros mais formais tanto na língua oral quanto na língua escrita. $O$ pronome "te" como sujeito, mesmo que ausente das gramáticas e dos livros didáticos modernos, é bastante freqüente em conversas informais. "Lui" e "lei" como sujeito, apesar de confortavelmente instalados no uso há vários anos, ainda se mostram pouco adequados, por exemplo, ao fazerem referência a personagens ilustres em textos orais ou escritos.

Abandonando a esfera micro dos desafios lingüísticos da nova realidade italiana ao modelo proposto como LE, cabe notar também que a língua privilegiada pelo aprendiz é a "língua viva" - aquela utilizada pelos falantes na península hoje - devido à posição de destaque da Itália contemporânea e à busca dos mercados de trabalho europeus pelos brasileiros a partir de meados dos anos 80 . Ou seja, nas últimas duas décadas, quando os reflexos dessa dinâmica da língua começaram a atravessar o Atlântico, as motivações para o estudo se diversificaram e se alargaram do lado de cá. Os atuais 
aprendizes podem ter como expectativa ler a Divina Comédia no original, participar da comunidade da igreja católica e estudar arte - em consonância com as motivações mais tradicionais -, além de entrar em contato com a família distante ou fazer uma pós-graduação numa cidade da península. Tudo isso, é óbvio, implica um conhecimento e uma habilidade por parte do professor que permitam ou facilitem a mobilidade desse aprendiz no complexo espaço lingüístico italiano.

SANTIPOLO (2002:190) propõe que, entre os objetivos de um curso de língua estrangeira, seja incluída a "consciência da variação", que ele define como "a tomada de consciência da existência das diversas variantes (diafásicas, diamésicas, diatópicas e diastráticas) de uma dada língua e a capacidade, ainda que parcial, de reempregá-las" ${ }^{\prime 10}$. Concordando com a afirmação do autor, meu ponto de vista é que, hoje, nós, professores de italiano como LE, devido ao momento que atravessa a língua italiana e às recentes exigências de nossos aprendizes, não podemos nos furtar a desenvolver nossa própria competência sociolingüística e a aprofundar conhecimentos no que diz respeito à história lingüística italiana. Acredito que apenas assumindo a postura de professor/pesquisador interessado nessa importante dinâmica, aqui brevemente resumida, poderemos fazer frente às questões e necessidades de nossos estudantes de maneira mais segura.

Paralelamente à questão colocada por nosso campo específico de trabalho - qual italiano ensinar? -, convém atentar para o fato de que o professor de línguas estrangeiras não mais é visto como mero transmissor de um código lingüístico asséptico, não lhe dizendo respeito apenas o terreno

10 "la presa di coscienza dell' esistenza delle diverse varietà (diafasiche, diamesiche, diatopiche e diastratiche) di una data lingua e la capacità, seppure parziale, di reimpiegarle". 
técnico da correção, mas também aquele culturalmente mais comprometido da comunicação e da expressão identitária. Assim, não podemos esquecer que os ecos do processo de italianização lingüística da península aportaram no Brasil em concomitância com a imagem de uma Itália moderna e européia - dando origem a novas motivações para o estudo-, num cenário em que ensinar língua estrangeira é desenvolver a competência comunicativa, ou seja, dar conta de todas essas dimensões que se referem ao contexto da aprendizagem e ao contexto de uso da língua.

Resumindo, os aprendizes hoje podem desejar se aproximar do italiano para sonhar ou para se comunicar com eficiência ${ }^{11}$, em contextos diversos, e nós, professores de LE, somos incumbidos, pelas novas abordagens e pela especificidade do momento da língua com a qual trabalhamos, de facilitarmos tanto o sonho quanto a comunicação.

O objetivo deste texto era o de sensibilizar o profissional ou estudante da língua para a complexidade e a riqueza da situação lingüística italiana, produto de um desenvolvimento histórico particular, e evidenciar o fato de que apenas o conhecimento dessa realidade poderá promover a clareza e a serenidade para definirmos as propostas de nossas aulas e para nos posicionarmos diante das incertezas de um campo em saudável movimento. Os desafios para o professor da área aqui apontados, ainda que árduos, poderiam ser incluídos entre os desafios de ensinar línguas nas sociedades complexas, levantados por BALBONI (2002), cabendo-nos, sem dúvida, enfrentá-los.

Abstract: Il presente lavoro si propone di offrire un panorama del processo di italianizzazione linguistica della

11 Em minha tese de doutorado (CHIARINI, 2002), explicito e contextualizo essa função dupla do ensino/ aprendizagem da língua italiana: o italiano para o sonho e o italiano para a comunicação. 
penisola italiana, sottolineando la ricchezza e la complessità della situazione che ne è risultata. Partendo dalla premessa che la lezione d'italiano come lingua straniera non è $e$ non deve essere immune dalla dinamica della lingua nello scenario dove è parlata, l'obiettivo di questo testo è, dunque, quello di sensibilizzare l'insegnante o l'apprendente a tale dinamica e evidenziare il fatto che soltanto la conoscenza di questa realtà consentirà una maggior chiarezza nella definizione dei contenuti linguistici e culturali delle lezioni $e$ dell'atteggiamento pii critico $e$ sicuro nei confronti delle incertezze e ambiguità di questo campo in salutare movimento.

\section{Referências bibliográficas}

BALBONI, P. E. Didattica dell'italiano a stranieri. Roma: Bonacci Editore \& Università per Stranieri di Siena, 1994

. Le sfide di Babele - Insegnare le lingue nelle società complesse. Torino: UTET Libreria, 2002.

BENUCCI, A. La lingua italiana descritta nelle grammatiche per stranieri. Rassegna Italiana di Linguistica Applicata, 3, 1997.

BERRUTO, G. Sociolinguistica dell'italiano contemporaneo. Roma: La Nuova Italia Scientifica, 1997.

BREEN, M. P. The social context of language learning - a neglected situation. Studies in Second Language Acquisition, 7, 1986.

CASTELLANI, A. Italiano dell'uso medio o italiano senz' aggettivi? Studi Linguistici Italiani, 17, 1991.

CASTELLANI POLLIDORI, O. La lingua di plastica. Studi Linguistici Italiani, 16, 1990. 
. La plastica nel parlato. In DE MAURO, T. (org.) Come parlano gli italiani. Scandicci (FI): La Nuova Italia, 1994.

CHIARINI, A.M. Representações em torno de uma paixão: a língua italiana em Belo Horizonte. Tese de Doutorado, Faculdade de Letras, UFMG, 2002.

COLEMAN, H. (org.) Society and the language classroom. Cambridge: Cambridge University Press, 1996.

CORTELAZZO, M. Avviamento critico allo studio della dialettologia italiana. III. Lineamenti di italiano popolare. Pisa: Pacini, 1.972.

COVERI, L., BENUCCI, A. \& DIADORI P. Le varietà dell'italiano - Manuale di sociolinguistica italiana. Roma: Bonacci Editore \& Università per Stranieri di Siena, 1998.

D'ACHILLE, P. L'italiano contemporaneo. Bologna: Il Mulino, 2003.

DE MAURO, T. Storia linguistica dell' Italia unita. Bologna: Zanichelli, 1963.

Per lo studio dell'italiano popolare unitario. In ROSSI, A. Lettere da una tarantata. Bari: Laterza, 1970.

DE MAURO, T. \& VEDOVELLI, M. La diffusione dell'italiano nel mondo e le vie dell'emigrazione: problemi istituzionali e sociolinguistici - La prospettiva degli anni '90. In CENTRO STUDI EMIGRAZIONE. La diffusione dell'italiano nel mondo e le vie dell'emigrazione - Retrospettiva storico-istituzionale e attualità. Roma: Centro Studi Emigrazione, 1996.

HOLLIDAY, A. Appropriate methodology and social context. Cambridge: Cambridge University Press, 1994. 
LORENZETTI, L. L'italiano contemporaneo. Roma: Carocci, 2002.

MIONI, A. Italiano tendenziale: osservazioni su alcuni aspetti della standardizzazione. In Scritti linguistici in onore di G. $B$. Pellegrini. Pisa: Pacini, 1983.

PASOLINI, P. P. Diálogo com Pasolini - Escritos (1957-1984). São Paulo: Instituto Cultural Ítalo-Brasileiro e Nova Stella, 1986.

SABATINI, F. L'italiano dell'uso medio: una realtà tra le varietà linguistiche italiane. In HOLTUS, G. \& RADTKE, E. (orgs.) Gesprochenes Italienisch in Geschichte und Gegenwart. Tübingen: Narr, 1985.

. Il parlato e la storia moderna dell'italiano. In DE MAURO, T. (org.) Come parlano gli italiani. Scandicci (FI): La Nuova Italia Editrice, 1994.

SANTIPOLO, M. Dalla Sociolinguistica alla Glottodidattica. Torino: UTET Libreria, 2002

SERIANNI, L. Il problema della norma linguistica nell'italiano. Annali dell' 'Università per Stranieri di Perugia, 7, 1986.

SOBRERO, A. A. Gli stili del parlato. In DE MAURO, T. (org.) Come parlano gli italiani. Scandicci (FI): La Nuova Italia Editrice, 1994.

STEINBERG, J. O historiador e a questione della lingua. In BURKE, P. \& PORTER, R. História social da linguagem. São Paulo: Fundação Editora da UNESP, 1997.

VEDOVELLI, M. L'italiano parlato dagli italiani e l'italiano appreso dai non italiani. In DE MAURO, T. (org.) Come parlano gli italiani. Scandicci (FI): La Nuova Italia, 1994. 